Review Article

\title{
Digital twin: a concept in evolution
}

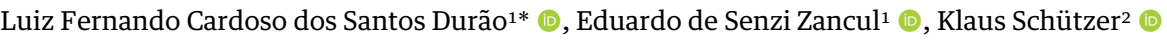 \\ ${ }^{1}$ Departamento de Engenharia de Produção, Escola Politécnica, Universidade de São Paulo - USP, São Paulo, SP, Brasil \\ ${ }^{2}$ Universidade Federal do ABC - UFABC, Santo André, SP, Brasil
}

\begin{abstract}
Digital Twin is defined as a realistic digital model of an object's physical state, representing its interaction with the environment in the real world. The research on Digital Twin has been advancing intensively in recent years. As a result of an emerging and broad research topic, various interpretations and Digital Twin applications have been developed. In this scenario, there is an opportunity to research the Digital Twin types and understand the concept evolvement. This paper provides an overview of the Digital Twin concept, classifies the existing body of literature, and discusses the Digital Twin evolution. Therefore, this research applies a combination of methods, including bibliometrics, natural language processing, and content analysis. The results show an expansion of Digital Twin's role from an enabler of cyber-physical systems to a product lifecycle data integration and processing platform.
\end{abstract}

Keywords: digital twin, advanced manufacturing, natural language analysis, Industry 4.0.

\section{Introduction}

In the new industrial era, physical and virtual worlds are constructed together into cyber-physical systems (Schluse et al., 2018), and a Digital Twin (DT) paves the way for cyber-physical integration (Desai et al., 2020; Haag \& Anderl, 2018; Qi \& Tao, 2018; Romero et al., 2018; Terkaj et al., 2019; Xu et al., 2018). A DT collects and evaluates the information from the physical world, supporting real-time simulation. This concept is built on the ideas of the Internet of Things and Industry 4.0 (Biffl et al., 2017; Golizadeh Akhlaghi et al., 2020; He \& Bai, 2021; Moyne \& Iskandar, 2017; Qiao et al., 2019; Schilling et al., 2019; Zhao et al., 2019).

Digital Twin is a way to deal with the complexity brought by digitalization (Vachalek et al., 2017). It contributes to transparency and to create a real-time production control (Uhlemann et al., 2017a). It can also contribute to the physical model to perform an optimized solution (Qi \& Tao, 2018) and comprises the different properties and information across multiple lifecycle phases (Stark \& Damerau, 2019). "A digital twin is a digital representation of a unique active product ... that comprises its selected characteristics, properties, conditions, and behaviors by means of models, information, and data within a single or even across multiple life cycle phases" (Stark \& Damerau, 2019). A Digital Twin implementation is still complex, and most studies demonstrate partial process views (Kannan \& Arunachalam, 2019; Kaur et al., 2020; Raj \& Surianarayanan, 2020; Rajesh et al., 2019; Schmetz et al., 2020; Uhlemann et al., 2017a). One of the hypotheses for this gap between theory and practice is the different interpretations of how a Digital Twin can be applied. Even considering the vast literature that has been produced on this topic, a consensus has not been reached.

To explore the various DT interpretations, a systematic literature review, merging bibliometrics and content analysis (Carvalho et al., 2013), was carried out. A natural language analysis was applied to cluster the Digital Twin types.

This article is structured as follows. Section 2 describes the research procedures for the systematic literature review. Section 3 discusses the different Digital Twin interpretations. Section 4 presents a discussion on the topic. Finally, Section 5 draws some concluding remarks and recommendations for further research.

\section{Research design}

The research design in this paper combines quantitative and qualitative strategies. It merges a bibliometric and content analysis to investigate a research topic, as they are complementary methods (Carvalho et al., 2013).

The bibliometric approach is particularly useful for large sample sizes since it focuses on metrics based on the number of publications and the metadata. On the other hand, the content analysis focuses on an in-depth review of the sample but allows analytical flexibility (Durão et al., 2017; Duriau et al., 2007). These approaches are used to probe the existing literature and identify relevant patterns, works, and authors of the particular field of research, and investigate the evolution of the publications stratified by journals (Durão et al., 2017).

Received: January 22, 2021. Accepted: April 8, 2021.

${ }^{*}$ Corresponding author: Luiz Fernando Cardoso dos Santos Durão. E-mail: luiz.durao@usp.br 


\subsection{Sampling}

An initial sample was established using the ISI Web of Science and Scopus databases. The search was performed in September 2020 by considering papers (or reviews) in peer-reviewed journals with a five-year time frame. The following search string was used: ("Digital Twin" OR "Digital Twin*” OR "Digital Shadow") AND (LIMIT-TO (SUBJAREA, “ENGI”) OR LIMIT-TO (SUBJAREA, “COMP”)) AND (LIMIT-TO (LANGUAGE, "English")). This first search resulted in 967 entries in the ISI Web of Science and 1822 entries in Scopus. 699 papers were common to the two databases. Hence, in total, there were 2090 different papers to be analyzed.

The first filtering criterion was based on keyword selection. The strings considered on the keyword were "Digital Twin", "Digital Factory", "Digital Thread", "Digital Shadow", "Smart Factory", and "Smart Manufacturing". The exclusion created a list with 1061 papers to be analyzed.

All selected publications had been published from 2015 to 2020, in 497 different sources. Among the journals, the "Procedia CIRP" has thirty six publications, "Journal of Manufacturing Systems" has thirty-six publications, the "IEEE Access" published twenty-nine papers, and the "International Journal of Production Research" has sixteen papers in the sample.

\subsection{Data analysis}

The final sample was analyzed in depth through bibliometrics and content analysis. First, bibliometric techniques were applied, using software VOSViewer (van Eck \& Waltman, 2010) for co-citations network analysis.

After that, a Term Frequency-Inverse Document Frequency (TF-IDF) analysis was performed to identify similarities between the articles' content, as shown in Equation 1 (Shaikh et al., 2017).

$w_{i, j}=t f_{i, j} \cdot \log \left(\frac{N}{d f_{i}}\right)$

$t f_{i, j}=$ number of occurences of $i$ in $j$

$d f_{i}=$ number of documents containing $i$

$N=$ total number of documents

With the TF-IDF calculated for every paper, a cluster analysis was performed to classify the observations into groups with similar characteristics (Hastie et al., 2009). An unsupervised Principal Component Analysis (PCA) model was performed.

Principal components are a sequence of projections of data ordered in variance. The purpose of this analysis is to derive a set of low-dimensional features from a much broader set while still preserving as much variance as possible. The idea is to see how each Digital Twin interpretation group is presented in a dispersion plot and creates similarity groups (Hastie et al., 2009).

Finally, the content analysis considered 59 papers published from 2017-2020. The papers selected for the content analysis were the most cited ones from each cluster, weighted by its publication year, complemented with a snowball addition of relevant articles.

\section{Digital twin types}

A Principal Component Analysis was performed on the papers' content to identify the Digital Twin types. This analysis was performed by using a natural language processing tool TF-IDF. The results of the different clusters and the number of citations are presented in Figure 1.

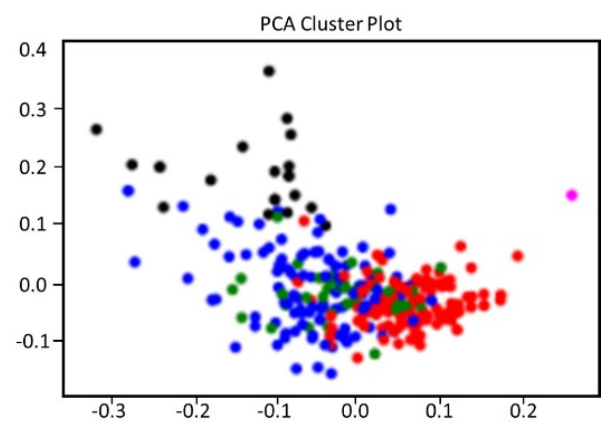

Figure 1. PCA cluster analysis. 
In Figure 1, it is possible to see the existence of three main clusters (black, blue, and red) and one additional cluster (green) that overlaps the other clusters, having its specific characteristics. The numbered sequence ( 1 to 4) represents the concept of evolution. Table 1 presents the most relevant papers in each cluster.

Table 1. Cluster analysis.

\begin{tabular}{|c|c|c|c|}
\hline Cluster number & Number of papers & Main papers & Color on figure 2 \\
\hline 1 & 174 & $\begin{array}{l}\text { El Saddik (2018), Lu \& Xu (2018), Rodič (2017), } \\
\text { Schluse et al. (2018) }\end{array}$ & green \\
\hline 2 & 339 & $\begin{array}{l}\text { Ma et al. (2019), Qi \& Tao (2018), Schleich et al. } \\
\text { (2017), Tao \& Zhang (2017), Uhlemann et al. } \\
\text { (2017a) }\end{array}$ & blue \\
\hline 3 & 83 & $\begin{array}{l}\text { Ding et al. (2019), Kritzinger et al. (2018), } \\
\text { Negri et al. (2017), Tao et al. (2019a) }\end{array}$ & black \\
\hline 4 & 465 & $\begin{array}{l}\text { Bazilevs et al. (2015), Ivanov (2020), Rosen et al. } \\
\text { (2015), Tao et al. (2019b), Zhang et al. (2019) }\end{array}$ & red \\
\hline
\end{tabular}

Cluster 1 (green) describes the Digital Twin as a "virtual representation of what has been produced" (Alam \& El Saddik, 2017). In this cluster, the authors define the Digital Twin as a new simulation model paradigm (Rodič, 2017). Besides, it brings different applications of Digital Twin (Raj \& Surianarayanan, 2020; Canedo, 2016). Digital Twin is not only a simulation tool but also a tool to monitor the whole product lifecycle.

In cluster 2 (blue), the authors suggest that smart systems need simulation technology to implement their functionality (Schluse et al., 2018). Simulation is a common method for industrial planning, depending mostly on the proper interface. Data is collected through sensors interconnected in an IoT system providing a reusable source for simulation (Lu et al., 2019). The Digital Twin is essential to provide the subsystems all required information (Barbosa et al., 2018; Brenner \& Hummel, 2017; Havard et al., 2019). Besides, it should be able to import background data, component information, and configuration information from the physical component (Liu et al., 2019a; Park et al., 2019; Zhuang et al., 2018). The Digital Twin is used to integrate different existing IT systems, i.e., Product Lifecycle Management (PLM), Manufacturing Execution Systems (MES), etc. Digital Twin is a way of mapping components on product lifecycle physical and virtual data and the interaction between them. It is initiated based on digital knowledge from the product design phase. The physical product and environmental knowledge is also embedded in the product 3D model, which forms the initiation of the Digital Twin (Wang \& Wang, 2019b). A virtual reality-based 3D digital model can also be deployed (Wang \& Wang, 2019a). It can facilitate designers to perform design activities (Tao et al., 2017, 2019b). By enabling cyberphysical synchronization with the MES, physical equipment, and design model, it changes the concept of serial design to an individualized design (Liu et al., 2019b).

Cluster 3 (black) discusses how to use the physical model's data to improve operations and development at the virtual model. According to the authors of this cluster, it is challenging to identify problems in smart manufacturing quickly. A way to do that efficiently would be using the vast amount of data captured on the physical model. Hence, big data is considered an essential part of Digital Twin. Without that property of transiting between the physical and the digital, the use of the captured data would not be feasible (Qi \& Tao, 2018). In this cluster, the authors also discuss the use of data collected to predict actions in the physical world. The Digital Twin contributes to creating a multi-modal data acquisition process that uses data analytics to predict future results of the object being studied (Uhlemann et al., 2017a). This kind of data is deduced from physical data and is defined as virtual data (Moyne \& Iskandar, 2017; Tao \& Zhang, 2017).

Finally, cluster 4 (red) considers Digital Twin as a very realistic model of the state of the product and its behavior in the interaction with the physical world (Rosen et al., 2015). For these authors, the simulation is a core functionality of a Digital Twin (Bigoni \& Hesthaven, 2020; Burghardt et al., 2020). They show different applications that capture data using IoT technologies and use them to simulate behaviors - using prediction models, simulated factory plans, etc., to forecast the product outcomes in different environments - and provide insights for future activities.

After the cluster definition, each cluster's most relevant papers were analyzed using the research methodology employed (Table 2) and DT application-(Table 3). The research methodology employed was classified into four categories (Table 2): 1) experiment - when use cases were implemented as a test for the technology developed; 2) case study - when an implemented DT was studied; 3) framework development - when a DT model was 
presented as a result for the research; 4) literature review - when systematic review methodologies were employed to define DT.

Table 2. Papers research methodology.

\begin{tabular}{cccccc}
\hline Methodology & $\mathbf{2 0 1 7}$ & $\mathbf{2 0 1 8}$ & $\mathbf{2 0 1 9}$ & $\mathbf{2 0 2 0}$ & Total \\
\hline Experiment & 5 & 3 & 9 & 7 & 24 \\
Case study & 4 & 7 & 5 & 3 & 19 \\
Framework development & 1 & 2 & 3 & 2 & 8 \\
Literature review & 1 & 1 & 1 & 5 & 8 \\
Total & $\mathbf{1 1}$ & $\mathbf{1 3}$ & $\mathbf{1 8}$ & $\mathbf{1 7}$ & $\mathbf{5 9}$ \\
\hline
\end{tabular}

Table 3. Papers DT application.

\begin{tabular}{cccccc}
\hline DT main application & $\mathbf{2 0 1 7}$ & $\mathbf{2 0 1 8}$ & $\mathbf{2 0 1 9}$ & $\mathbf{2 0 2 0}$ & Total \\
\hline Data acquisition & 2 & 3 & 1 & 2 & 8 \\
Data integration & 4 & 3 & 7 & 6 & 20 \\
Data processing & 3 & 2 & 3 & 5 & 13 \\
Lifecycle management & 2 & 5 & 7 & 4 & 18 \\
Total & $\mathbf{1 1}$ & $\mathbf{1 3}$ & $\mathbf{1 8}$ & $\mathbf{1 7}$ & $\mathbf{5 9}$ \\
\hline
\end{tabular}

The DT applications were classified into four categories (Table 3): 1) Data acquisition - DT is used as a capture system, as an IoT feature; 2) Data integration - DT is applied as an integration framework for different data types; 3) Data processing - DT is applied to predict information; and 4) Lifecycle management - DT is used to manage the product lifecycle. Table 4 presents the relationship between the research methodology and DT application and lists the main publications in each group.

Table 4. Methodology x DT application.

\begin{tabular}{|c|c|c|}
\hline DT interpretation of use & methodology & Reference \\
\hline \multirow{3}{*}{ Data acquisition } & Case study & El Saddik (2018), Park et al. (2019), Schuh et al. (2018) \\
\hline & Experiment & Siegert et al. (2017), Uhlemann et al. (2017a), Zhuang et al. (2018) \\
\hline & Literature review & Kaur et al. (2020) \\
\hline \multirow{5}{*}{ Data integration } & Case study & $\begin{array}{c}\text { Barbosa et al. (2018), Brenner \& Hummel (2017), Ding et al. (2019), } \\
\text { Erdős et al. (2020), Liu et al. (2019a, 2019b), Uhlemann et al. (2017b), } \\
\text { Zhang et al. (2020) }\end{array}$ \\
\hline & Experiment & $\begin{array}{c}\text { Alam \& El Saddik (2017), Greif et al. (2020), He \& Bai (2021), Kannan \& } \\
\text { Arunachalam (2019), Schilling et al. (2019), Wang \& Wu (2020), } \\
\text { Zhao et al. (2019) }\end{array}$ \\
\hline & Framework development & Cheng et al. (2018), Erkoyuncu et al. (2020), Tao et al. (2019a) \\
\hline & Literature review & Kritzinger et al. (2018), Negri et al. (2017), Wang et al. (2020) \\
\hline & Case study & Moyne \& Iskandar (2017), Rodič (2017) \\
\hline \multirow[t]{3}{*}{ Data processing } & Experiment & $\begin{array}{l}\text { Golizadeh Akhlaghi et al. (2020), Havard et al. (2019), Park et al. (2020), } \\
\text { Qiao et al. (2019), Raza et al. (2020), Schluse et al. (2018), Stark et al. } \\
\text { (2019), Stavropoulos et al. (2020), Vachalek et al. (2017) }\end{array}$ \\
\hline & Framework development & Qi \& Tao (2018) \\
\hline & Literature review & Valckenaers (2020) \\
\hline \multirow{4}{*}{ Lifecycle management } & Case study & $\begin{array}{l}\text { Burghardt et al. (2020), Lu \& Xu (2018), Tao et al. (2017), Terkaj et al. } \\
\text { (2019), Xu et al. (2018) }\end{array}$ \\
\hline & Experiment & $\begin{array}{l}\text { Haag \& Anderl (2018), Lu et al. (2019), Rajesh et al. (2019), Schleich et al. } \\
\text { (2017), Wang \& Wang (2019b) }\end{array}$ \\
\hline & Framework development & $\begin{array}{l}\text { Ma et al. (2019), Schmetz et al. (2020), Tao et al. (2019b), Tao \& Zhang } \\
\text { (2017) }\end{array}$ \\
\hline & Literature review & Jones et al. (2020), Lim et al. (2020), Roy et al. (2020) \\
\hline
\end{tabular}




\section{Discussion}

The analyses of the different clusters and the main papers in each group show a temporal evolution about the DT understanding. The use of DT as a Data acquisition tool is well defined in the literature. In this vision, DT is represented as an enabler of Cyber-physical systems (Zhuang et al., 2018) that support the production system's coupling with its digital equivalent (Uhlemann et al., 2017a). This vision can be related to cluster 1 that brings the initial efforts to define the DT concept and implement it. There are few new studies on this understanding once it is argued that this DT view can be expanded (Lu \& Xu, 2018; Qi \& Tao, 2018).

The second understanding defines DT as an integration platform. In this view, the integration between virtual and physical is described as the process of collecting data from manufacturing sites in the physical world and transmitting those data into the information systems. In recent years, many new ITs have been applied to collect different data types concerning the full production lifecycle (Cheng et al., 2018). Examples are related to the integration between the PDM (Product Data Management), PLM (Product Lifecycle Management), and ERP (Enterprise Resource Planning) systems (Lu \& Xu, 2018). It is directly related to cluster 2 that brings the main idea of a DT. There are different case studies considering this understanding showing the maturity of this concept.

The third understanding of DT is a technology to process manufacturing data. On this understanding, the essence of a Digital Twin presents a middleware architecture that abstracts the shopfloor hardware to make realtime decisions (Yuqian $\mathrm{Lu} \& \mathrm{Xu}, 2018$ ). The data from the physical world are transmitted to the virtual models to perform simulations and validations. Simulation data are feedback to the physical world to respond to the changes, improve the operation, and increase the value. In the process of interaction between virtual and physical, the integration of data is inevitable (Qi \& Tao, 2018). It can be related to the third cluster, showing DT's ability to provide a real-time decision. The papers on this understanding are developing experiments to test this type of implementation.

Finally, the collaboration between the physical and virtual worlds is the key element on the fourth interpretation. IoT technologies allow communication to facilitate the exchange of information and the simulation process during the entire lifecycle of the product (Tao et al., 2019b). Digital Twin is more than a representation of the real world. It is a digital replica of a physical entity. It enables a seamless transfer of data by connecting the physical and virtual world (He \& Bai, 2021). This view is related to the fourth cluster, which shows DT's full potential as a product lifecycle management tool.

Therefore, Digital Twins are being related to the evolution of Industry 4.0 concepts and technologies. At the beginning of the DT developments, the main idea was to remotely repair components in the international space station (Glaessgen \& Stargel, 2012). With the evolution of sensing technologies in the shop-floor, the connection between DT and industry was defined through simulation (Lu et al., 2019). However, the lack of resources to collect and process data created a mixed understanding between DT and CPS. For the construction of a DT, data is needed. The CPS - which deals with the conversion of analogic to digital data - may be a way to collect and exploit this data.

With the evolution of software capabilities and hardware capacity, DT's understanding evolves in the direction of managing data from the entire lifecycle of a product. Therefore, it is necessary to develop a data model capable of connecting the different types of information and providing real-time reactions to the physical and digital sides.

There is an evolution of DT understanding and use as an initial technology for capturing data, to a data integration platform, a data processing tool, and a way to provide insights over the entire product lifecycle.

\section{Conclusion}

This research explored DT's different interpretations and discussed the technology evolution. At first, DT was only considered a way to create cyber-physical systems as a possible evolution of the IoT devices. Later, DT evolved to be considered an integration platform for various data, a processing platform capable of predicting results, and a technology to map the entire product lifecycle.

One common goal on the different understandings of Digital Twin is to perform the interconnection between the physical world and cyberspace of manufacturing. A Digital Twin carries both the physical object's information and the information of the virtual model.

This research has limitations due to the search strings considered in the literature review and the researched databases. As future research, it opens space for exploring each defined DT implementation in the industry. The evolution of DT concepts has its bases on creating a backbone theory on data integration and processing. DT's basic principles lay on understanding the lifecycle of a product and applying this analytical capacity to forecast product outcomes and evolution. 


\section{References}

Alam, K. M., \& El Saddik, A. (2017). C2PS: A digital twin architecture reference model for the cloud-based cyber-physical systems. IEEE Access: Practical Innovations, Open Solutions, 5, 2050-2062. http://dx.doi.org/10.1109/ACCESS.2017.2657006.

Barbosa, S., Silva, F. P., Rafael, L., \& Otto, R. B. (2018). Virtual assistant to real time training on industrial environment. Amsterdam: IOS Press. http://dx.doi.org/10.3233/978-1-61499-898-3-33.

Bazilevs, Y., Deng, X., Korobenko, A., Di Scalea, F. L., Todd, M. D., \& Taylor, S. G. (2015). Isogeometric fatigue damage prediction in large-scale composite structures driven by dynamic sensor data. Journal of Applied Mechanics, Transactions ASME, 82(9), 091008. https://doi.org/10.1115/1.4030795

Biffl, S., Gerhard, D., \& Lüder, A. (2017). Multi-disciplinary engineering for cyber-physical production systems: Data models and software solutions for handling complex engineering projects. Switzerland: Springer Nature. https://doi.org/10.1007/978-3-31956345-9.

Bigoni, C., \& Hesthaven, J. S. (2020). Simulation-based anomaly detection and damage localization: an application to structural health monitoring. Computer Methods in Applied Mechanics and Engineering, 363, 112896.

http://dx.doi.org/10.1016/j.cma.2020.112896.

Brenner, B., \& Hummel, V. (2017). Digital twin as enabler for an innovative digital shopfloor management system in the ESB logistics learning factory at reutlingen - University. Procedia Manufacturing, 9, 198-205.

http://dx.doi.org/10.1016/j.promfg.2017.04.039.

Burghardt, A., Szybicki, D., Gierlak, P., Kurc, K., Pietruś, P., \& Cygan, R. (2020). Programming of industrial robots using virtual reality and digital twins. Applied Sciences (Switzerland), 10(2), 486. http://dx.doi.org/10.3390/app10020486.

Canedo, A. (2016). Industrial IoT lifecycle via digital twins. In Proceedings of the Eleventh IEEE/ACM/IFIP International Conference on Hardware/Software Codesign and System Synthesis (CODES '16) (Article 29, pp. 1). New York, USA: Association for Computing Machinery. https://doi.org/10.1145/2968456.2974007.

Carvalho, M. M., Fleury, A., \& Lopes, A. P. (2013). An overview of the literature on technology roadmapping (TRM): contributions and trends. Technological Forecasting and Social Change, 80(7), 1418-1437. http://dx.doi.org/10.1016/j.techfore.2012.11.008.

Cheng, Y., Zhang, Y., Ji, P., Xu, W., Zhou, Z., \& Tao, F. (2018). Cyber-physical integration for moving digital factories forward towards smart manufacturing : a survey. International Journal of Advanced Manufacturing Technology, 97(1-4), 1209-1221. http://dx.doi.org/10.1007/s00170-018-2001-2.

Desai, N., Ananya, S. K., Bajaj, L., \& Periwal, A. (2020). Cyber-physical systems and digital twins. Rev, 2019(80), 74-80. http://dx.doi.org/10.1007/978-3-030-23162-0.

Ding, K., Chan, F. T. S., Zhang, X., Zhou, G., \& Zhang, F. (2019). Defining a digital twin-based cyber-physical production system for autonomous manufacturing in smart shop floors. International Journal of Production Research, 57(20), 6315-6334 http://dx.doi.org/10.1080/00207543.2019.1566661

Durão, L. F. C. S., Grotti, M. V. F., Maceta, P. R. M., Zancul, E. de S., Berssaneti, F. T., \& Carvalho, M. M. (2017). A review of the soft side in project management: concept, trends and challenges. GEPROS: Revista Gestão da Produção Operações e Sistemas, 12(2), 157-176. http://dx.doi.org/10.15675/gepros.v12i2.1644.

Duriau, V., Reger, R., \& Pfarrer, M. D. (2007). A content analysis of the content analysis literature in organization studies research themes, data sources, and methodological refinements. Organizational Research Methods, 10(1), 5-34. http://dx.doi.org/10.1177/1094428106289252.

El Saddik, A. (2018). Digital twins: the convergence of multimedia technologies. IEEE MultiMedia, 25(2), 87-92. http://dx.doi.org/10.1109/MMUL.2018.023121167.

Erdős, G., Paniti, I., \& Tipary, B. (2020). Transformation of robotic workcells to digital twins. CIRP Annals, 69(1), $149-152$. http://dx.doi.org/10.1016/j.cirp.2020.03.003.

Erkoyuncu, J. A., del Amo, I. F., Ariansyah, D., Bulka, D., Vrabič, R., \& Roy, R. (2020). A design framework for adaptive digital twins. CIRP Annals, 69(1), 145-148. http://dx.doi.org/10.1016/j.cirp.2020.04.086.

Glaessgen, E. H., \& Stargel, D. S. (2012). The digital twin paradigm for future NASA and U.S. Air force vehicles. In 53rd AIAA/ASME/ASCE/AHS/ASC Structures, Structural Dynamics and Materials Conference (pp. 1-14). Reston: American Institute of Aeronautics and Astronautic. https://doi.org/10.2514/6.2012-1818

Golizadeh Akhlaghi, Y., Badiei, A., Zhao, X., Aslansefat, K., Xiao, X., Shittu, S., \& Ma, X. (2020). A constraint multi-objective evolutionary optimization of a state-of-the-art dew point cooler using digital twins. Energy Conversion and Management, 211, 112772. http://dx.doi.org/10.1016/j.enconman.2020.112772.

Greif, T., Stein, N., \& Flath, C. M. (2020). Peeking into the void: digital twins for construction site logistics. Computers in Industry, 121, 103264. http://dx.doi.org/10.1016/j.compind.2020.103264.

Haag, S., \& Anderl, R. (2018). Digital twin: proof of concept. Manufacturing Letters, 15, 64-66. http://dx.doi.org/10.1016/j.mfglet.2018.02.006.

Hastie, T., Tibshirani, R., \& Friedman, J. (2009). The elements of statistical learning: data mining, inference, and prediction (2nd ed.). ew York: Springer.

Havard, V., Jeanne, B., Lacomblez, M., \& Baudry, D. (2019). Digital twin and virtual reality: a co-simulation environment for design and assessment of industrial workstations. Production \& Manufacturing Research, 7(1), 472-489. http://dx.doi.org/10.1080/21693277.2019.1660283.

He, B., \& Bai, K. J. (2021). Digital twin-based sustainable intelligent manufacturing: a review. Advances in Manufacturing, 9(1), 1. 
Ivanov, D. (2020). Predicting the impacts of epidemic outbreaks on global supply chains: a simulation-based analysis on the coronavirus outbreak (COVID-19/SARS-CoV-2) case. Transportation Research Part E, Logistics and Transportation Review, 136, 101922 .

Jones, D., Snider, C., Nassehi, A., Yon, J., \& Hicks, B. (2020). Characterising the digital twin: a systematic literature review. CIRP Journal of Manufacturing Science and Technology, 29, 36-52. http://dx.doi.org/10.1016/j.cirpj.2020.02.002.

Kannan, K., \& Arunachalam, N. (2019). A digital twin for grinding wheel: an information sharing platform for sustainable grinding process. Journal of Manufacturing Science and Engineering, 141(2), 021015. https://doi.org/10.1115/1.4042076.

Kaur, M. J., Mishra, V. P., \& Maheshwari, P. (2020). The convergence of digital Twin, IoT, and machine learning: transforming data into action. In M. Farsi, A. Daneshkhah, A. Hosseinian-Far \& H. Jahankhani (Eds.), Digital Twin technologies and smart cities Cham: Springer International Publishing. https://doi.org/10.1007/978-3-030-18732-3_1.

Kritzinger, W., Karner, M., Traar, G., Henjes, J., \& Sihn, W. (2018). Digital Twin in manufacturing: a categorical literature review and classification. IFAC-PapersOnLine, 51(11), 1016-1022. http://dx.doi.org/10.1016/j.ifacol.2018.08.474.

Lim, K. Y. H., Zheng, P., \& Chen, C. H. (2020). A state-of-the-art survey of Digital Twin: techniques, engineering product lifecycle management and business innovation perspectives. Journal of Intelligent Manufacturing, 31(6), 1313-1337. http://dx.doi.org/10.1007/s10845-019-01512-w.

Liu, J., Zhou, H., Tian, G., Liu, X., \& Jing, X. (2019a). Digital twin-based process reuse and evaluation approach for smart process planning. International Journal of Advanced Manufacturing Technology, 100(5-8), 1619-1634. http://dx.doi.org/10.1007/s00170018-2748-5.

Liu, Q., Zhang, H., Leng, J., \& Chen, X. (2019b). Digital twin-driven rapid individualised designing of automated flow-shop manufacturing system. International Journal of Production Research, 57(12), 3903-3919. http://dx.doi.org/10.1080/00207543.2018.1471243.

Lu, Y., Min, Q., Liu, Z., \& Wang, Y. (2019). An IoT-enabled simulation approach for process planning and analysis : a case from engine re- manufacturing industry. International Journal of Computer Integrated Manufacturing, 32(4-5), 413-429. http://dx.doi.org/10.1080/0951192X.2019.1571237.

Lu, Y., \& Xu, X. (2018). Resource virtualization: a core technology for developing cyber-physical production systems. Journal of Manufacturing Systems, 47, 128-140. http://dx.doi.org/10.1016/j.jmsy.2018.05.003.

Ma, X., Tao, F., Zhang, M., Wang, T., \& Zuo, Y. (2019). Digital twin enhanced human-machine interaction in product lifecycle. Procedia CIRP, 83, 789-793. http://dx.doi.org/10.1016/j.procir.2019.04.330.

Moyne, J., \& Iskandar, J. (2017). Big data analytics for smart manufacturing: case studies in semiconductor manufacturing. Processes, 5(3), 39. http://dx.doi.org/10.3390/pr5030039.

Negri, E., Fumagalli, L., \& Macchi, M. (2017). A review of the roles of digital twin in CPS-based production systems. Procedia Manufacturing, 11, 939-948. http://dx.doi.org/10.1016/j.promfg.2017.07.198.

Park, K. T., Lee, J., Kim, H.-J., \& Noh, S. D. (2020). Digital twin-based cyber physical production system architectural framework for personalized production. International Journal of Advanced Manufacturing Technology, 106(5-6), 1787-1810. http://dx.doi.org/10.1007/s00170-019-04653-7.

Park, K. T., Nam, Y. W., Lee, H. S., Im, S. J., Noh, S. D., Son, J. Y., \& Kim, H. (2019). Design and implementation of a digital twin application for a connected micro smart factory. International Journal of Computer Integrated Manufacturing, 32(6), 596-614. http://dx.doi.org/10.1080/0951192X.2019.1599439.

Qi, Q., \& Tao, F. (2018). Digital twin and big data towards smart manufacturing and industry 4.0: 360 degree comparison. IEEE Access : Practical Innovations, Open Solutions, 6, 3585-3593. http://dx.doi.org/10.1109/ACCESS.2018.2793265.

Qiao, Q., Wang, J., Ye, L., \& Gao, R. X. (2019). Digital twin for machining tool condition prediction. Procedia CIRP, 81, 13881393. http://dx.doi.org/10.1016/j.procir.2019.04.049.

Raj, P., \& Surianarayanan, C. (2020). Digital twin: the industry use cases. Advances in Computers, 117(1), 285-320. http://dx.doi.org/10.1016/bs.adcom.2019.09.006.

Rajesh, P. K., Manikandan, N., Ramshankar, C. S., Vishwanathan, T., \& Sathishkumar, C. (2019). Digital twin of an automotive brake pad for predictive maintenance. Procedia Computer Science, 165, 18-24. http://dx.doi.org/10.1016/j.procs.2020.01.061.

Raza, M., Kumar, P. M., Hung, D. V., Davis, W., Nguyen, H., \& Trestian, R. (2020). A digital twin framework for industry 4.0 enabling next-gen manufacturing. In ICITM 2020 - 2020 9th International Conference on Industrial Technology and Management (pp. 73-77). New York: IEEE. https://doi.org/10.1109/ICITM48982.2020.9080395.

Rodič, B. (2017). Industry 4.0 and the new simulation modelling paradigm. Organizacija, 50(3), 193-207. http://dx.doi.org/10.1515/orga-2017-0017.

Romero, D., Mattsson, S., \& Fast-berglund, Å. (2018). Advances in production management systems: smart manufacturing for industry 4.0. In IFIP WG 5.7 International Conference, APMS 2018 (Vol. 536). Switzerland: Springer Nature. https://doi.org/10.1007/978-3-319-99707-0

Rosen, R., Von Wichert, G., Lo, G., \& Bettenhausen, K. D. (2015). About the importance of autonomy and digital twins for the future of manufacturing. IFAC-PapersOnLine, 28(3), 567-572. http://dx.doi.org/10.1016/j.ifacol.2015.06.141.

Roy, R. B., Mishra, D., Pal, S. K., Chakravarty, T., Panda, S., Chandra, M. G., Pal, A., Misra, P., Chakravarty, D., \& Misra, S. (2020). Digital twin: current scenario and a case study on a manufacturing process. International Journal of Advanced Manufacturing Technology, 107(9-10), 3691-3714. http://dx.doi.org/10.1007/s00170-020-05306-w.

Schilling, K., Stanetzky, D., \& Brecher, C. (2019). A mixed reality application for linked data in engineering and production. In MuC'19: Proceedings of Mensch und Computer 2019 (pp. 673-676). ACM. http://dx.doi.org/10.1145/3340764.3344889 
Schleich, B., Anwer, N., Mathieu, L., \& Wartzack, S. (2017). Shaping the digital twin for design and production engineering. CIRP Annals - Manufacturing Technology, 66(1), 141-144. https://doi.org/10.1016/j.cirp.2017.04.040.

Schluse, M., Priggemeyer, M., Atorf, L., \& Rossmann, J. (2018). Experimentable digital twins-streamlining simulation-based systems engineering for industry 4.0. IEEE Transactions on Industrial Informatics, 14(4), 1722-1731. http://dx.doi.org/10.1109/TII.2018.2804917.

Schmetz, A., Lee, T. H., Hoeren, M., Berger, M., Ehret, S., Zontar, D., Min, S. H., Ahn, S. H., \& Brecher, C. (2020). Evaluation of Industry 4.0 data formats for digital twin of optical components. International Journal of Precision Engineering and Manufacturing, 7(3), 573-584. http://dx.doi.org/10.1007/s40684-020-00196-5.

Schuh, G., Jussen, P., \& Harland, T. (2018). The digital shadow of services: a reference model for comprehensive data collection in MRO services of machine manufacturers. Procedia CIRP, 73, 271-277. http://dx.doi.org/10.1016/j.procir.2018.03.318.

Shaikh, F. K., Zeadally, S., \& Exposito, E. (2017). Enabling technologies for social internet of things. IEEE Systems Journal, 11(2), 983-994. http://dx.doi.org/10.1109/JSYST.2015.2415194.

Siegert, J., Schlegel, T., Groß, E., \& Bauernhansl, T. (2017). Standardized coordinate system for factory and production planning. Procedia Manufacturing, 9(711), 127-134. http://dx.doi.org/10.1016/j.promfg.2017.04.032.

Stark, R., \& Damerau, T. (2019). Digital twin. In S. Chatti \& T. Tolio (Eds.), CIRP Encyclopedia of Production Engineering. Berlin: Springer. http://dx.doi.org/10.1007/978-3-642-35950-7_16870-1.

Stark, R., Fresemann, C., \& Lindow, K. (2019). Development and operation of Digital Twins for technical systems and services. CIRP Annals, 68(1), 129-132. http://dx.doi.org/10.1016/j.cirp.2019.04.024.

Stavropoulos, P., Papacharalampopoulos, A., \& Athanasopoulou, L. (2020). A molecular dynamics based digital twin for ultrafast laser material removal processes. International Journal of Advanced Manufacturing Technology, 108(1-2), 413-426. http://dx.doi.org/10.1007/s00170-020-05387-7.

Tao, F., \& Zhang, M. (2017). Digital twin shop-floor: a new shop-floor paradigm towards smart manufacturing. IEEE Access: Practical Innovations, Open Solutions, 5, 20418-20427. http://dx.doi.org/10.1109/ACCESS.2017.2756069.

Tao, F., Cheng, J., Qi, Q., Zhang, M., Zhang, H., \& Sui, F. (2017). Digital twin-driven product design, manufacturing and service with big data. International Journal of Advanced Manufacturing Technology, http://dx.doi.org/10.1007/s00170-017-0233-1.

Tao, F., Qi, Q., Wang, L., \& Nee, A. Y. C. (2019a). Digital twins and cyber-physical systems toward smart manufacturing and industry 4.0: correlation and comparison. Engineering, 5(4), 653-661. http://dx.doi.org/10.1016/j.eng.2019.01.014.

Tao, F., Sui, F., Liu, A., Qi, Q., Zhang, M., Song, B., Guo, Z., Lu, S. C. Y., \& Nee, A. Y. C. (2019b). Digital twin-driven product design framework. International Journal of Production Research, 57(12), 3935-3953.

http://dx.doi.org/10.1080/00207543.2018.1443229.

Terkaj, W., Gaboardi, P., Trevisan, C., Tolio, T., \& Urgo, M. (2019). A digital factory platform for the design of roll shop plants. CIRP Journal of Manufacturing Science and Technology, 26, 88-93. http://dx.doi.org/10.1016/j.cirpj.2019.04.007.

Uhlemann, T. H. J., Lehmann, C., \& Steinhilper, R. (2017a). The digital twin: realizing the cyber-physical production system for industry 4.0. Procedia CIRP, 61, 335-340. http://dx.doi.org/10.1016/j.procir.2016.11.152.

Uhlemann, T. H. J., Schock, C., Lehmann, C., Freiberger, S., \& Steinhilper, R. (2017b). The digital twin: demonstrating the potential of real time data acquisition in production systems. Procedia Manufacturing, 9, 113-120. http://dx.doi.org/10.1016/j.promfg.2017.04.043

Vachalek, J., Bartalsky, L., Rovny, O., Sismisova, D., Morhac, M., \& Loksik, M. (2017). The digital twin of an industrial production line within the industry 4.0 concept. In Proceedings of the 201721 st International Conference on Process Control (PC 2017) (pp. 258-262). New York: IEEE. http://dx.doi.org/10.1109/PC.2017.7976223.

Valckenaers, P. (2020). Perspective on holonic manufacturing systems: PROSA becomes ARTI. Computers in Industry, 120 103226. http://dx.doi.org/10.1016/j.compind.2020.103226.

van Eck, N. J., \& Waltman, L. (2010). Software survey: VOSviewer, a computer program for bibliometric mapping. Scientometrics, 84(2), 523-538. http://dx.doi.org/10.1007/s11192-009-0146-3.

Wang, K. J., Lee, T. L., \& Hsu, Y. (2020). Revolution on digital twin technology: a patent research approach. International Journal of Advanced Manufacturing Technology, 107(11-12), 4687-4704. http://dx.doi.org/10.1007/s00170-020-05314-w

Wang, A. X., \& Wang, X. (2019a). Virtual reality of 3D digital factory based on coastal environment. Journal of Coastal Research, 83, 507-512. https://doi.org/10.2112/SI83-085.1.

Wang, X. V., \& Wang, L. (2019b). Digital twin-based WEEE recycling, recovery and remanufacturing in the background of Industry 4.0. International Journal of Production Research, 57(12), 3892-3902. http://dx.doi.org/10.1080/00207543.2018.1497819.

Wang, Y., \& Wu, Z. (2020). Model construction of planning and scheduling system based on digital twin. International Journal of Advanced Manufacturing Technology, 109(7-8), 2189-2203. http://dx.doi.org/10.1007/s00170-020-05779-9.

Xu, Y., Bondaletova, N. F., Kovalev, V. I., \& Komrakov, A. V. (2018). Digital twin concept in managing industrial capital construction projects life cycle. In 2018 Eleventh International Conference "Management of Large-Scale System Development" (MLSD) (pp. 1-3). New York: IEEE. https://doi.org/10.1109/MLSD.2018.8551867.

Zhang, H., Yan, Q., \& Wen, Z. (2020). Information modeling for cyber-physical production system based on digital twin and AutomationML. International Journal of Advanced Manufacturing Technology, 107(3-4), 1927-1945. http://dx.doi.org/10.1007/s00170-020-05056-9.

Zhang, J., Ding, G., Zou, Y., Qin, S., \& Fu, J. (2019). Review of job shop scheduling research and its new perspectives under Industry 4.0. Journal of Intelligent Manufacturing, 30(4), 1809-1830. http://dx.doi.org/10.1007/s10845-017-1350-2.

Zhao, G., Cao, X., Xiao, W., Zhu, Y., \& Cheng, K. (2019). Digital twin for NC machining using complete process information expressed by STEP-NC standard. In CACRE2019: Proceedings of the 2019 4th International Conference on Automation, Control 
and Robotics Engineering (ACM International Conference Proceeding Series). New York: ACM. http://dx.doi.org/10.1145/3351917.3351979.

Zhuang, C., Liu, J., \& Xiong, H. (2018). Digital twin-based smart production management and control framework for the complex product assembly shopfloor. International Journal of Advanced Manufacturing Technology, 96(1-4), 1149-1163. http://dx.doi.org/10.1007/s00170-018-1617-6. 